\title{
A systematic review and meta-analysis of the relative efficacy and safety of treatment regimens for HIV- associated cerebral toxoplasmosis: is trimethoprim- sulfamethoxazole a real option?
}

\author{
AV Hernandez, ${ }^{1,2 *}$ P Thota, ${ }^{3 *}$ D Pellegrino, ${ }^{4}$ V Pasupuleti, ${ }^{3}$ VA Benites-Zapata, ${ }^{5}$ A Deshpande, ${ }^{6,7}$ AC Penalva de Oliveira ${ }^{8}$ \\ and JE Vidal ${ }^{8,9,10}$ \\ ${ }^{1}$ School of Medicine, Universidad Peruana de Ciencias Aplicadas (UPC), Lima, Peru, ${ }^{2}$ Health Outcomes and Clinical \\ Epidemiology Section, Department of Quantitative Health Sciences, Lerner Research Institute, Cleveland Clinic, Cleveland, OH, \\ USA, ${ }^{3}$ Department of Medicine, Case Western Reserve University, Cleveland, OH, USA, ${ }^{4}$ Department of Infectious Diseases, \\ Instituto de Infectologia Emilio Ribas, Sao Paulo, Brazil, ${ }^{5}$ Center for Public Health Research, Research Institute, Faculty of \\ Medicine, Universidad de San Martin de Porres, Lima, Peru, ${ }^{6}$ Medicine Institute Center for Value Based Care Research, \\ Cleveland Clinic, Cleveland, OH, USA, ${ }^{7}$ Department of Infectious Diseases, Medicine Institute, Cleveland Clinic, Cleveland, OH, \\ USA, ${ }^{8}$ Department of Neurology, Instituto de Infectologia Emilio Ribas, Sao Paulo, Brazil, ${ }^{9}$ Divisão de Clínica de Moléstias \\ Infecciosas e Parasitárias, Hospital das Clínicas, Faculdade de Medicina da Universidade de Sao Paulo, Sao Paulo, Brazil and \\ ${ }^{10}$ Laboratório de Protozoologia, Instituto de Medicina Tropical de São Paulo, Faculdade de Medicina da Universidade de São \\ Paulo, São Paulo, Brazil
}

\section{Objectives}

The objective of this study was to perform a systematic review and meta-analysis of the literature to evaluate the efficacy and safety of therapies for cerebral toxoplasmosis in HIV-infected adults. The pyrimethamine plus sulfadiazine $(\mathrm{P}-\mathrm{S})$ combination is considered the mainstay therapy for cerebral toxoplasmosis and pyrimethamine plus clindamycin $(\mathrm{P}-\mathrm{C})$ is the most common alternative treatment. Although trimethoprim-sulfamethoxazole (TMP-SMX) has potential advantages, its use is infrequent.

Methods

We searched PubMed and four other databases to identify randomized controlled trials (RCTs) and cohort studies. Two independent reviewers searched the databases, identified studies and extracted data. Risk ratios (RRs) were pooled across studies using random-effects models.

Results

Nine studies were included (five RCTs, three retrospective cohort studies and one prospective cohort study). In comparison to P-S, treatment with P-C or TMP-SMX was associated with similar rates of partial or complete clinical response [P-C: RR 0.87; 95\% confidence interval (CI) 0.70-1.08; TMP-SMX: RR 0.97; 95\% CI 0.78-1.21], radiological response (P-C: RR 0.92; 95\% CI 0.82-1.03), skin rash (P-C: RR 0.81; 95\% CI 0.56-1.17; TMP-SMX: RR 0.17; 95\% CI 0.02-1.29), gastrointestinal impairment (P-C: RR 5.16; 95\% CI 0.66-40.11), and drug discontinuation because of adverse events (P-C: RR 0.32; 95\% CI 0.07-1.47). Liver impairment was more frequent with P-S than P-C (P-C vs. P-S: RR 0.48; 95\% CI 0.24-0.97).

\section{Conclusions}

The current evidence fails to identify a superior regimen in terms of relative efficacy or safety for the treatment of HIV-associated cerebral toxoplasmosis. Use of TMP-SMX as preferred treatment may be consistent with the available evidence and other real-world considerations. Larger comparative studies are needed.

Keywords: cerebral toxoplasmosis, HIV infection, toxoplasmic encephalitis.

Accepted 23 February 2016

Correspondence: Dr José E. Vidal, Department of Neurology, Instituto de Infectologia Emilio Ribas, Av. Doutor Arnaldo 165, Cerqueira César, São Paulo 01246-900, Brazil. Tel: +5511 38961200; e-mail: josevibe@gmail.com "These authors contributed equally to the study.

\section{Introduction}

Highly active antiretroviral therapy (HAART) has significantly reduced the incidence, prevalence, and case- 
fatality rates of cerebral toxoplasmosis in HIV-infected patients from both developed and developing countries $[1,2]$. Treatment of cerebral toxoplasmosis has been relatively successful in comparison to other opportunistic infections; however, cerebral toxoplasmosis still represents a poor prognostic determinant in patients with advanced disease and severe immunodeficiency $[1,3,4]$.

Although the first case of HIV-associated cerebral toxoplasmosis was described in 1980 [5], there have been only a few randomized controlled trials and cohort studies comparing different regimens for the treatment of AIDSassociated cerebral toxoplasmosis [6,7]. Thus, although HIV-associated cerebral toxoplasmosis is quite a common world-wide problem, there is a scarcity of evidence regarding optimal therapy. The preferred initial therapy for cerebral toxoplasmosis in Department of Health and Human Services of the USA (DHHS), European AIDS Clinical Society (EACS), and British HIV Association (BHIVA) guidelines is the combination of pyrimethamine plus sulfadiazine $(\mathrm{P}-\mathrm{S})$, and pyrimethamine plus clindamycin $(\mathrm{P}-\mathrm{C})$ is the preferred alternative regimen [8-10]. Trimethoprim-sulfamethoxazole (TMP-SMX) usually appears as an additional alternative in these three guidelines, but other recommendations [11] indicate this combination and $\mathrm{P}-\mathrm{S}$ as furst-line therapies. In clinical practice, however, TMP-SMX use is infrequent when $\mathrm{P}-\mathrm{C}$ and P-S are available. In contrast, TMP-SMX is the first choice in Africa and in other developing regions, particularly where other regimens are not available or where there is experience with TMP-SMX. TMP-SMX has potential advantages (i.e. tolerability, posology, parenteral formulation and accessibility) and remains an attractive option. Pyrimethamine is a standard use drug approved by the Food and Drug Administration (FDA) in 1953 but its price has increased worryingly, with a negative impact on both public health and individual patient care. In addition, regimens including pyrimethamine require the use of folinic acid, a medication usually unavailable in most resource-limited settings. The DHHS guidelines mention that pyrimethamine will soon no longer be available in retail pharmacies in the USA (http:// aidsinfo.nih.gov/guidelines/html/4/adult-and-adolescentoi-prevention-and-treatment-guidelines/0) and recommends it for patients with suspected or documented toxoplasmosis who do not have a history of sulfa allergy; TMP-SMX should be used as a substitute if pyrimethamine is not readily available. In this scenario, the optimal management of cerebral toxoplasmosis continues to be controversial, and evidence-based, clear alternatives to pyrimetamine are needed.
The purpose of this systematic review and meta-analysis was to evaluate the most effective and safest therapy for HIV-associated cerebral toxoplasmosis.

\section{Methods}

\section{Data sources and searches}

We performed a systematic search for publications using PubMed-Medline, CINAHL, Scopus, Web of Science and the Cochrane Library from database inception to 30 October 2014. Search strategies used subject headings and keywords with no language restrictions. The database searches were performed independently by two authors (PT and DP). The PubMed search strategy is available as supplementary data (Appendix S1). A manual search of references from recent reviews and relevant published original studies was also performed to identify relevant studies.

The following predetermined inclusion criteria were used: (1) studies evaluating the efficacy and safety of acute therapeutic regimens in HIV-infected patients with cerebral toxoplasmosis; (2) study population of patients > 18 years old. Our exclusion criteria were: (1) single drug regimen observational studies; (2) case series; (3) studies in which safety and efficacy data were not available or could not be extracted for each of the study groups. Efficacy outcomes of interest were clinical and radiological response. All adverse event data provided in the included studies were recorded for safety outcomes.

\section{Study selection and data extraction}

A list of retrieved articles was reviewed independently by two investigators (PT and DP) to choose potentially relevant articles, and any disagreements were discussed and resolved by consensus with one other author (AVH). Two reviewers (PT and DP) independently extracted and recorded data from included studies. The following information was extracted: age, gender, time since AIDS diagnosis, treatment regimens, duration of treatment, follow-up time, clinical and radiological responses, and adverse events. One other author $(\mathrm{AVH})$ reviewed the extractions for discrepancies, and the three authors (PT, DP and AVH) reached a consensus.

\section{Evaluation of study quality}

The quality of all included cohort studies was assessed independently by two authors (PT and VP) using the 
Newcastle-Ottawa scale (NOS) [12]. The NOS uses two different tools for case-control and cohort studies and consists of three parameters of quality: selection, comparability and exposure/outcome assessment. The NOS assigns a maximum of four points for selection, two points for comparability and three points for exposure or outcome. NOS scores of $\geq 7$ were considered to represent high-quality studies and NOS scores of 5-6 were considered to represent moderate quality.

The quality of all included randomized controlled trials (RCTs) was assessed independently by two authors (PT and VP) using The Cochrane Collaboration tool for assessing risk of bias [13]. The following items were evaluated: generation of the allocation sequence (selection bias); concealment of the allocation sequence (selection bias); blinding (detection and performance bias); blinding of participants and personnel to outcome assessment; incomplete outcome data (attrition bias); selective outcome reporting (reporting bias); and other biases. For each RCT, each item was described as having either a low risk of bias, a high risk of bias, or an unclear risk of bias. All discrepancies were addressed by a re-evaluation of the original article as a group (PT, VP and AVH).

\section{Data synthesis and analysis}

Our systematic review followed the recommendations of the Preferred Reporting Items for Systematic Reviews

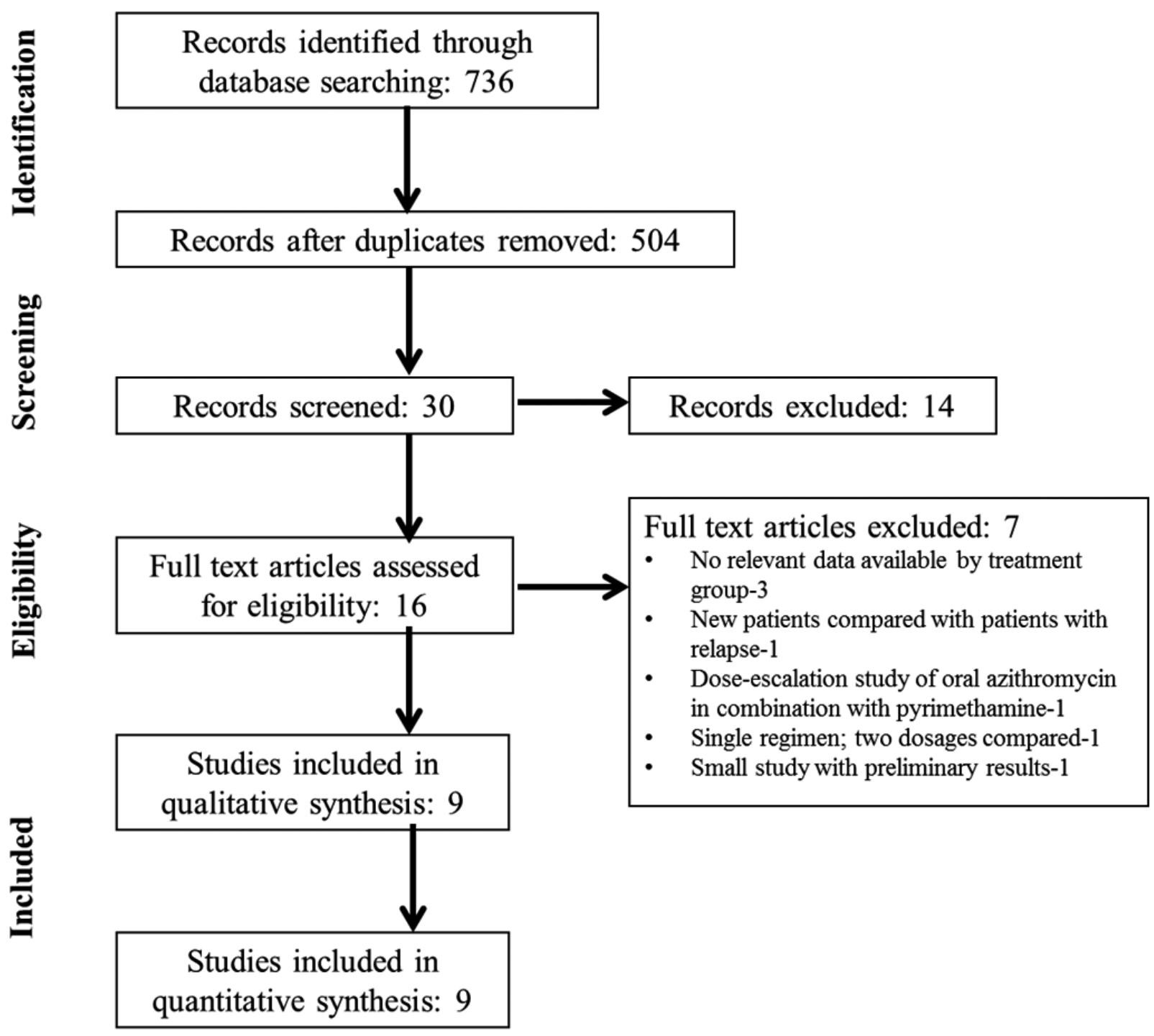

Fig. 1 Preferred Reporting Items for Systematic Reviews and Meta-Analyses (PRISMA) flow chart for the selected studies. 
and Meta-Analyses (PRISMA) collaboration [14]. DerSimonian and Laird random-effects models and the inverse variance method were used for all meta-analyses [15] to calculate pooled risk ratios and 95\% confidence intervals (CIs). $I^{2}$ values of 30-60\% represented a moderate level of heterogeneity. A $P$-value of $<0.1$ for $\chi^{2}$ was defined as indicating the presence of heterogeneity. Publication bias was illustrated using funnel plots and formally tested with Egger's test [16]. We used Review Manager for all statistical analyses (RevMan 5.0; The Cochrane Collaboration, Oxford, UK; http://tech.cochrane.org/revman/about-revman-5).

\section{Results}

\section{Eligible studies}

Of the 504 unique articles retrieved and screened by study title, 30 potentially relevant articles were selected based on relevance to the study topic. After screening the abstracts, 16 articles were found to fulfil the inclusion criteria and were selected for full-text review (Fig. 1). Nine articles $(n=692)$ assessing the efficacy and/or safety of acute therapeutic regimens in HIV-infected patients with cerebral toxoplasmosis were included in our systematic review and meta-analysis. Seven articles were excluded after full-text review (reasons for exclusion are listed in Fig. 1).

\section{Study characteristics}

Table 1 summarizes the main characteristics of the included studies. Of the nine included studies, five were RCTs [17-21], three were retrospective cohort studies [1,22,23] and one was a prospective cohort study [24]. Sample size ranged from 29 to 299 patients. The most commonly evaluated treatment regimen was P-S, which was one of the treatment arms in seven studies. Duration of treatment varied from 3 weeks to 6-8 weeks.

\section{Quality assessment and publication bias}

NOS quality scores for cohort studies ranged from 6 to 8 (Supporting Information Table S1a). The majority of the included RCTs were assessed as having a high risk of bias using the Cochrane tool, with no blinding of participants, personnel and outcome assessment as the main issues (Table S1b). The low number of studies in the pooled analyses $(<10)$ precluded us from evaluating for publication bias by funnel plot analysis. However, publication bias was minimized by a comprehensive

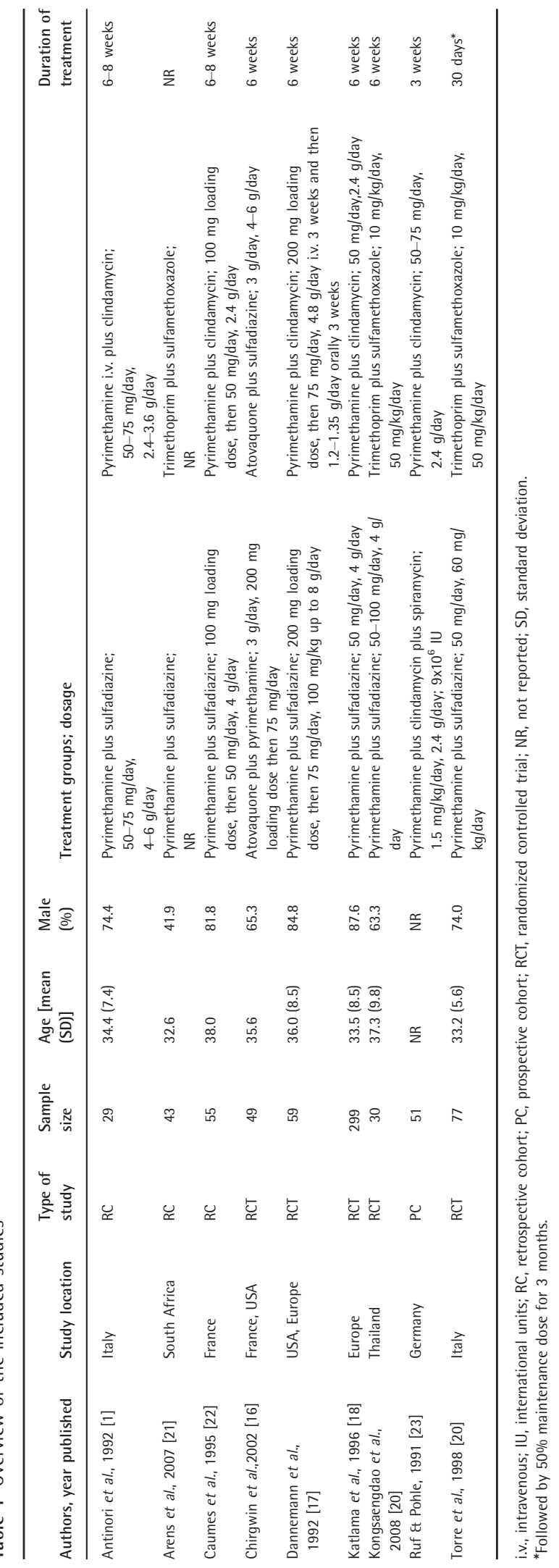




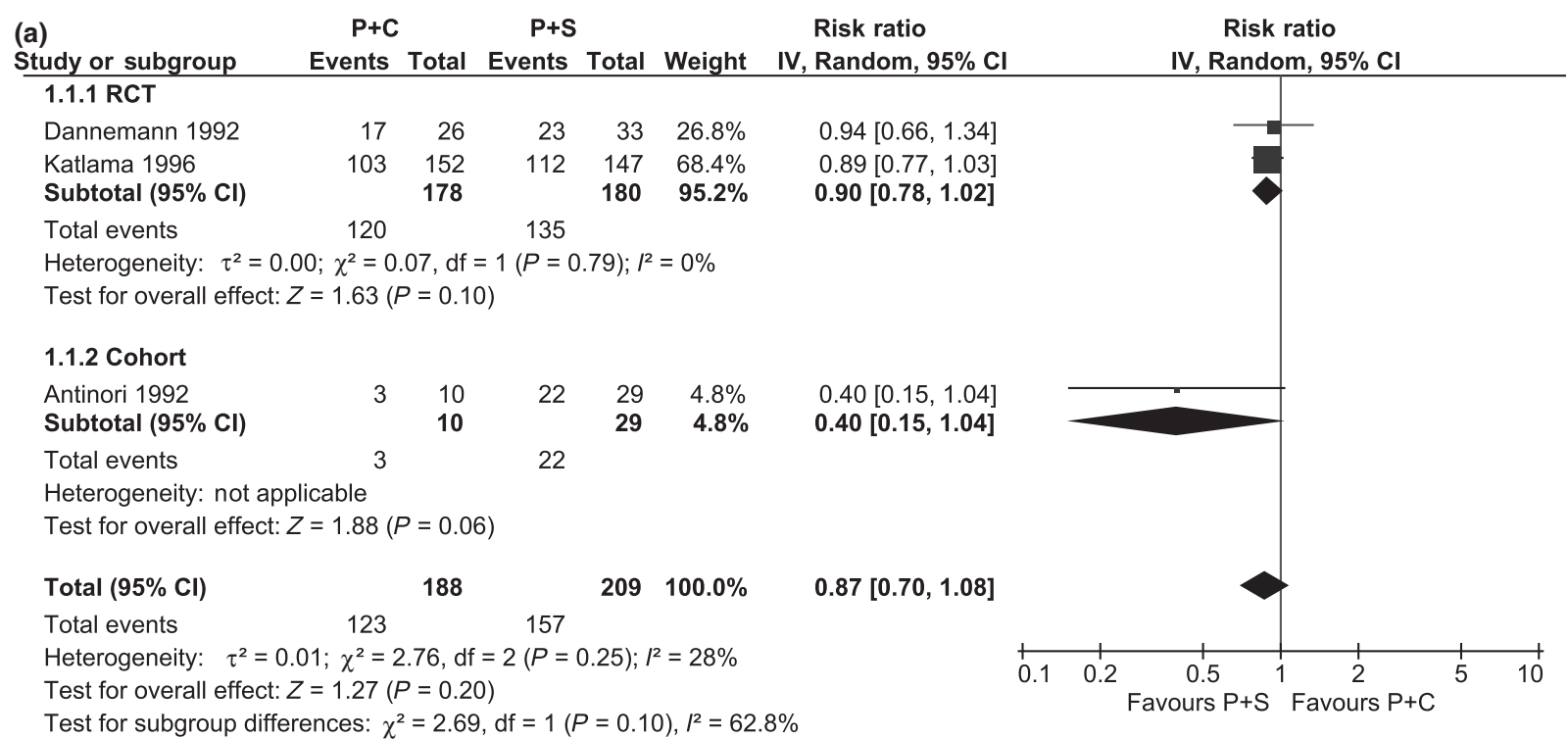

(b)

TMP-SMX

$\mathrm{P}+\mathrm{S}$

Risk ratio

Risk ratio

Study or subgroup Events Total Events Total Weight IV, Random, 95\% Cl 2.1.1 RCT

Torre 1998

Subtotal $(95 \% \mathrm{Cl})$

Total events

31
$\quad 40$
$\quad 40$

$\begin{array}{rrr}30 & 37 & 91.1 \% \\ & \mathbf{3 7} & \mathbf{9 1 . 1} \%\end{array}$

$0.96[0.76,1.20]$

Heterogeneity: not applicable

Test for overall effect: $Z=0.39(P=0.70)$

\subsubsection{Cohort}

Arens 2007

Subtotal $(95 \% \mathrm{Cl})$

Total events

Heterogeneity: not applicable

Test for overall effect: $Z=0.33(P=0.74)$

Total $(95 \% \mathrm{Cl})$

65

Total events

42

Heterogeneity: $\tau^{2}=0.00 ; \chi^{2}=0.19, \mathrm{df}=1(P=0.67) ; r^{2}=0 \%$

Test for overall effect: $Z=0.27(P=0.79)$

Test for subgroup differences: $\chi^{2}=0.19, \mathrm{df}=1(P=0.67), I^{2}=0 \%$

IV, Random, $95 \% \mathrm{Cl}$

Fig. 2 Partial or complete clinical response. (a) Pyrimethamine plus clindamycin (P-C) vs. pyrimethamine plus sulfadiazine (P-S). (b) Trimethoprim-sulfamethoxazole (TMP-SMX) vs. P-S. Cl, confidence interval; RCT, randomized controlled trial; IV, inverse variance.

search of databases without language and publication date restrictions.

\section{Meta-analyses}

Clinical and radiological efficacy

Treatment with P-S had a similar clinical efficacy when compared with P-C or TMP-SMX, with similar rates of partial or complete clinical response [P-C vs. P-S: risk ratio (RR) 0.87 ; 95\% confidence interval (CI) 0.70-1.08; $I^{2}=28 \%$; TMP-SMX vs. P-S: RR 0.97; 95\% CI 0.78-1.21;
$\left.I^{2}=0 \%\right]$ (Fig. 2) and radiological response (P-C vs. P-S: RR 0.92; 95\% CI 0.82-1.03; $I^{2}=0 \%$ ) (Fig. 3).

\section{Safety}

The rates of skin rash (P-C vs. P-S: RR 0.81; 95\% CI 0.56$1.17 ; I^{2}=53 \%$; TMP-SMX vs. P-S: RR 0.17; 95\% CI 0.02$1.29 ; I^{2}=0 \%$ ) (Figure S1), gastrointestinal impairment (PC vs. P-S: RR 5.16; 95\% CI 0.66-40.11; $I^{2}=56 \%$ ) (Figure S2), and drug discontinuation because of adverse events (P-C vs. P-S: RR 0.32; 95\% CI 0.07-1.47; $I^{2}=42 \%$ ) (Figure S3) were similar for P-S vs. P-C or TMP-SMX. Liver 


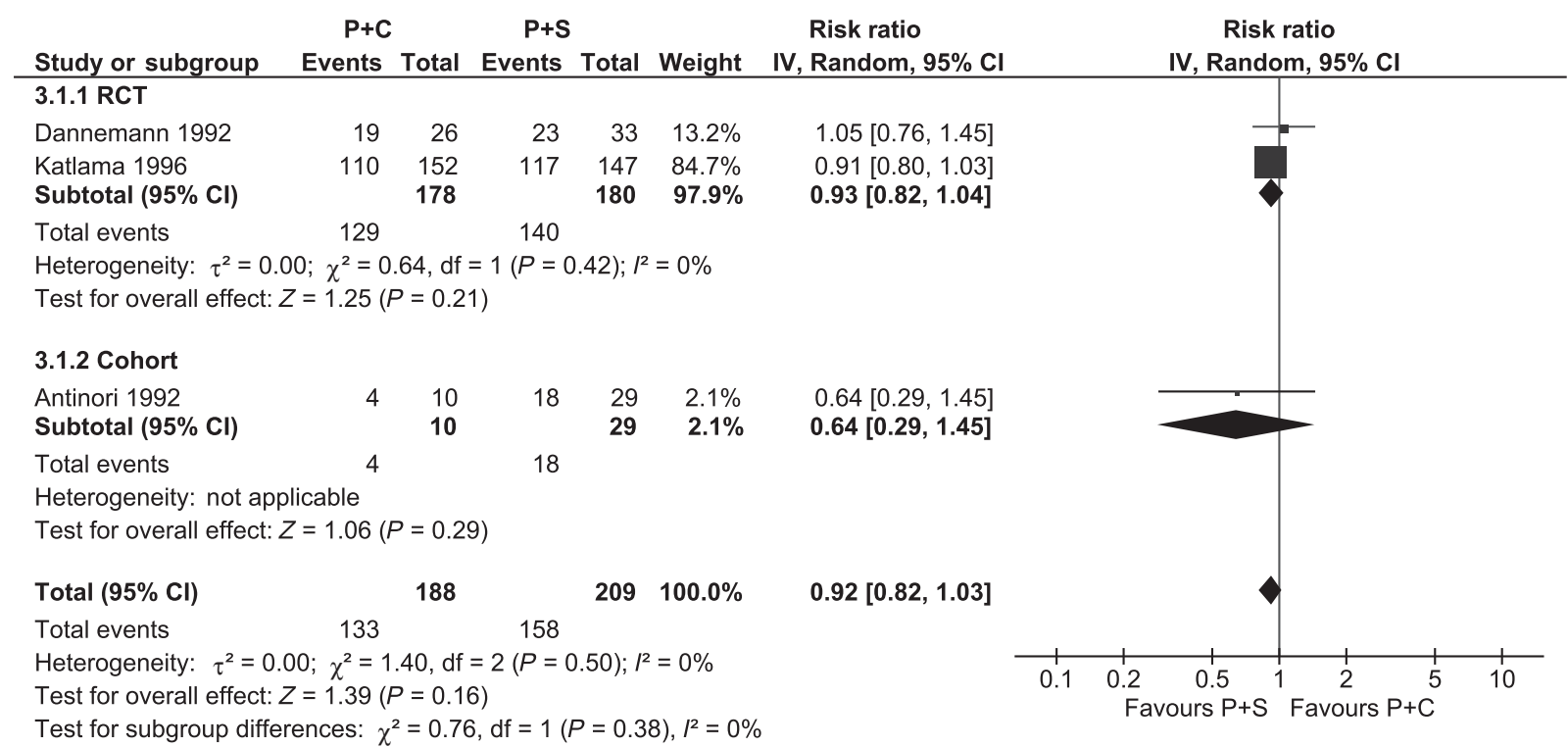

Fig. 3 Partial or complete radiological response for the comparison of pyrimethamine plus clindamycin (P-C) vs. pyrimethamine plus sulfadiazine (P-S). Cl, confidence interval; $\mathrm{RCT}$, randomized controlled trial.

impairment was more frequent for $\mathrm{P}-\mathrm{S} v s$. $\mathrm{P}-\mathrm{C}(\mathrm{P}-\mathrm{C} v s$. P-S: RR 0.48; 95\% CI 0.24-0.97) (Figure S4).

\section{Discussion}

In this systematic review and meta-analysis, we found that treatment with $\mathrm{P}-\mathrm{S}$ had similar relative clinical and radiological efficacy and similar safety when compared with P-C or TMP-SMX. Among adverse events, only liver impairment was more frequent with $\mathrm{P}-\mathrm{S}$ when compared with the P-C regimen.

The main objective of this study was to compare and evaluate the current evidence on various treatment regimens for cerebral toxoplasmosis and to explore the availability of alternative, better treatment regimens. Table 2 presents an overview of two previous reviews and the present study. The first study was a systematic review by The Cochrane Collaboration [6]. This review included only randomized double-blind trials. On evaluating three studies, two comparing P-S with P-C $[18,19]$ and one comparing P-S with TMP-SMX [21], the authors found similar rates of complete or partial clinical response between the regimens. The second study was a systematic review and meta-analysis [7], which included randomized and quasi-randomized controlled studies. On analysing five studies, three comparing P-S with P-C $[1,18,19]$ and two comparing P-S with TMP-SMX [20,21], the authors found similar rates of complete or partial clinical response and mortality outcomes between the regimens.
Interestingly, P-S showed substantial toxicity and intolerance when compared with P-C.

As only a limited number of randomized trials have been performed on this topic, we aimed to evaluate the treatment regimens for HIV-associated cerebral toxoplasmosis in a larger population by including comparative cohort studies. Our results are in congruence with those of the two previous reviews, confirming that treatment with P-S had similar efficacy and safety to P-C or TMPSMX. We found that only liver impairment was more frequent with $\mathrm{P}-\mathrm{S}$ when compared with $\mathrm{P}-\mathrm{C}$. Thus, the available evidence fails to identify any one superior regimen for the treatment of cerebral toxoplasmosis.

Cerebral toxoplasmosis has been the most common central nervous system disease in patients with AIDS from both developed and developing countries [25-27]. In the HAART era, the burden of cerebral toxoplasmosis was reduced particularly in developed countries and to a lesser extent in developing countries. The situation is more serious in scenarios with nonavailability of HAART. However, globally, cerebral toxoplasmosis continues to afflict patients for several reasons: [1] late HIV diagnosis; [2] noncompliance with HAART or preventive antimicrobial drugs; and [3] virological and immunological HAART failure [28]. For these reasons, cerebral toxoplasmosis poses a serious challenge in the management of HIV-infected patients.

Early recognition and prompt treatment of acute symptoms during the initial phase of cerebral toxoplasmosis reduces the risk of neurological sequelae and mortality. 
Table 2 Comparison of published systematic reviews on treatment of AIDS-associated cerebral toxoplasmosis

\begin{tabular}{|c|c|c|c|}
\hline & Dedicoat et al. [6] & Yan et al. [7] & Our study \\
\hline Year of publication & 2006 & 2013 & - \\
\hline Aim & $\begin{array}{l}\text { To determine the most effective therapy } \\
\text { for TE in HIV-infected adults }\end{array}$ & $\begin{array}{l}\text { To determine the therapy that is most } \\
\text { effective for primary prophylaxis of TE } \\
\text { or for treating HIV-infected patients } \\
\text { presenting with the first episode TE }\end{array}$ & $\begin{array}{l}\text { To evaluate the most effective and safe } \\
\text { therapy for cerebral toxoplasmosis in } \\
\text { HIV-infected adults }\end{array}$ \\
\hline Type of studies included & Randomized double-blinded trials & $\begin{array}{l}\text { Randomized and quasi-randomized } \\
\text { controlled trials }\end{array}$ & RCTs and cohort studies \\
\hline Search databases & $\begin{array}{l}\text { PubMed, EMBASE, AIDSearch and The } \\
\text { Cochrane Library }\end{array}$ & $\begin{array}{l}\text { PubMed, Google Scholar, EMBASE and } \\
\text { CENTRAL }\end{array}$ & $\begin{array}{l}\text { PubMed, CINAHL, Scopus, Web of Science } \\
\text { and The Cochrane Library }\end{array}$ \\
\hline Search cut-off date & November 2005 & September 2012 & October 2014 \\
\hline Number of studies included & Three trials & $\begin{array}{l}11 \text { trials (including five studies evaluating } \\
\text { treatment of TE) }\end{array}$ & $\begin{array}{l}\text { Five RCTs, three retrospective cohort } \\
\text { studies and one prospective cohort } \\
\text { study }\end{array}$ \\
\hline Total number of patients & 435 & $\begin{array}{l}1472 \text { ( } n=494 \text { in studies evaluating } \\
\text { treatment of TE) }\end{array}$ & 692 \\
\hline Study quality assessment & $\begin{array}{l}\text { The assessment was based on the quality } \\
\text { of allocation concealment, blinding, } \\
\text { baseline characteristics of patients, use } \\
\text { of intention-to-treat analysis and } \\
\text { completeness of follow-up }\end{array}$ & Jadad scale & $\begin{array}{l}\text { Cochrane risk of bias tool for RCTs; } \\
\text { Newcastle-0ttawa scale for cohort } \\
\text { studies }\end{array}$ \\
\hline Primary outcome & $\begin{array}{l}\text { Mortality, clinical response to treatment, } \\
\text { neurological outcome and serious } \\
\text { adverse events }\end{array}$ & $\begin{array}{l}\text { TE (when prophylactics used), mortality } \\
\text { and drug-limiting toxicity }\end{array}$ & $\begin{array}{l}\text { Clinical and radiological efficacy of } \\
\text { treatment and adverse effects }\end{array}$ \\
\hline Results & $\begin{array}{l}\text { Mortality (P-C vs. P-S: RR 1.41; 95\% Cl } \\
\text { 0.88-2.28; P-S vs. TMP-SMX: RR 0.0; } \\
\text { 95\% Cl 0.0-0.0); } \\
\text { partial or complete clinical response } \\
\text { (P-C vs. P-S: RR 0.95; } \\
\text { 95\% Cl 0.55-1.64; P-S vs. TMP-SMX: } \\
\text { RR 1.00; 95\% Cl 0.74-1.33); } \\
\text { adverse events (P-C vs. P-S: RR 0.95; } \\
\text { 95\% Cl 0.81-1.11; P-S vs. TMP-SMX: } \\
\text { RR 0.58; 95\% Cl 0.21-1.61); } \\
\text { radiological response (P-C vs. P-S: RR } \\
\text { 0.95; 95\% Cl 0.84-1.07; P-S vs. TMP- } \\
\text { SMX: RR 1.09; 95\% Cl 0.78-1.51) }\end{array}$ & $\begin{array}{l}\text { Episodes of TE (TMP-SMX vs. D-P: OR } \\
\text { 0.98; 95\% Cl 0.48-2.00); } \\
\text { mortality (TMP-SMX vs. D-P: OR 0.75; } \\
\text { 95\% Cl 0.53-1.06; P-S vs. P- C: OR } \\
\text { 0.66; 95\% Cl 0.37-1.17; P-S vs. TMP- } \\
\text { SMX: OR 0.12; 95\% Cl 0.01-1.39); } \\
\text { toxicity and intolerance (TMP-SMX vs. } \\
\text { D-P: OR 1.47; 95\% Cl 0.91-2.38; P-S } \\
\text { vs. P-C: OR 3.08; 95\% Cl 1.82-5.24; P- } \\
\text { S vs. TMP-SMX: OR 2.91; 95\% Cl 0.99- } \\
\text { 8.55); } \\
\text { clinical response (P-S vs. P-C: OR 1.63; } \\
\text { 95\% Cl 1.05-2.51; P-S vs. TMP-SMX: } \\
\text { OR 0.90; 95\% Cl 0.39-2.06) }\end{array}$ & $\begin{array}{l}\text { Partial or complete clinical response (P-C } \\
\text { vs. P-S: RR 0.87; } 95 \% \mathrm{Cl} 0.70-1.08 ; \\
\text { TMP-SMX vs. P-S: RR 0.97; 95\% Cl } \\
\text { 0.78-1.21); radiological response (P-C } \\
\text { vs. P-S: RR 0.92; 95\% Cl 0.82-1.03); } \\
\text { skin rash (P-C vs. P-S: RR 0.81; 95\% Cl } \\
\text { 0.56-1.17; TMP-SMX vs. P-S: RR 0.17; } \\
\text { 95\% Cl 0.02-1.29); } \\
\text { GI impairment (P-C vs. P-S: RR 5.16; } \\
\left.\text { 95\% Cl 0.66-40.11; } P^{2}=56 \%\right) ; \text { drug } \\
\text { discontinuation because of adverse } \\
\text { events (P-C vs. P-S: RR 0.32; 95\% Cl } \\
\text { 0.07-1.47); } \\
\text { liver impairment (P-C vs. P-S: RR 0.48; } \\
\text { 95\% Cl 0.24-0.97) }\end{array}$ \\
\hline Conclusions & $\begin{array}{l}\text { The available evidence fails to identify } \\
\text { any one superior regimen for the } \\
\text { treatment of TE. TMP-SMX appears to } \\
\text { be an effective alternative therapy for } \\
\text { TE in resource-poor settings where } \\
\text { pyrimethamine and sulfadiazine are } \\
\text { not available. }\end{array}$ & $\begin{array}{l}\text { The available evidence fails to identify } \\
\text { any one superior regimen for the } \\
\text { primary prophylaxis and treatment of } \\
\text { TE. Administration of TMP-SMX for } \\
\text { primary prophylaxis and treatment of } \\
\text { TE in patients with HIV infection is } \\
\text { consistent with the available data. }\end{array}$ & $\begin{array}{l}\text { Current evidence fails to identify one } \\
\text { superior regimen in terms of relative } \\
\text { efficacy or safety for the treatment of } \\
\text { HIV-associated cerebral toxoplasmosis. } \\
\text { Use of TMP-SMX as preferred } \\
\text { treatment is consistent with the } \\
\text { available evidence and other real-world } \\
\text { considerations. }\end{array}$ \\
\hline
\end{tabular}

$\mathrm{Cl}$, confidence interval; RR, risk ratio; TE, toxoplasmic encephalitis; RCT, randomized controlled trial; TMP-SMX, trimethoprim plus sulfamethoxazole; P$\mathrm{S}$, pyrimethamine plus sulfadiazine; P-C, pyrimethamine plus clindamycin; D-P, dapsone plus pyrimethamine; GI, gastrointestinal.

Historically, the regimen containing P-S has been preferred, and for patients who have contraindications for sulfadiazine use, the common alternative was P-C $[9,29]$. Approximately $70-90 \%$ of patients treated with these regimens demonstrate clinical and/or radiological improvement [30]. In clinical practice, however, treatment with P-S or P-C is beset with several problems, including adverse events, poor tolerability, complex posology, and the absence of parenteral formulations (a major problem in patients with alteration of mental status). In this context, evaluation of alternative treatments continues to be a challenge. In patients with no allergies to sulfa drugs, TMP-SMX has been considered as a potential alternative $[9,10]$. One of the limitations to more widespread use of TMP-SMX is the lack of clinician expertise with this regimen in settings wherein P-S and P-C are available. Although diverging from classical and "paradigmatic" therapeutic management choices is not easy, a critical review of evidence can be useful in this scenario. TMPSMX is routinely used in several settings, particularly in developing countries when $\mathrm{P}-\mathrm{S}$ or $\mathrm{P}-\mathrm{C}$ is not available. Evidence from these settings is scarce, as demonstrated in 
our review, where eight of nine included studies were conducted in developed countries.

The ideal RCT to identify the optimal treatment of cerebral toxoplasmosis should compare TMP-SMX with $\mathrm{P}-\mathrm{S}$ using a noninferior design, be multicentre and double-blinded, and have a robust sample size. Using clinical response (i.e. complete plus partial response) as the primary outcome, the results from Torre et al.'s 1998 trial [21] (clinical response: TMP-SMX $\operatorname{arm}=78 \%$ and P-S arm $=81 \%$ ), an alpha of 5\% and a power of $90 \%$, then 690 patients are required to be $90 \%$ sure that the upper limit of a one-sided 95\% CI (or equivalently a 90\% two-sided CI) will exclude a difference in favour of the P-S arm of more than 12\% (i.e. the noninferiority limit). Major international efforts are necessary to conduct this study, particularly in developing countries.

Currently, potential advantages of TMP-SMX over P-S or P-C include: [1] the convenience of the lower pill burden and dosing frequency and the availability of intravenous formulations; current guidelines suggest an option of parenteral TMP-SMX usage as initial treatment in severely ill patients [9]; [2] the availability of several generic TMP-SMX formulations with the consequent impact on cost-effectiveness and increased accessibility; [3] prevention of Pneumocystis jirovecii pneumonia, other bacterial infections, and malaria [9,31]; and [4] the convenience of use simplifying the early initiation of HAART, which is associated with increased survival of HIV-infected patients with most opportunistic diseases.

Our study has some limitations. First, the quality of included studies was moderate to good. Most of the RCTs did not use blinding of treatments, which is essential to reduce information bias. We also included cohort studies, which have a higher probability of bias than RCTs; however, cohort studies were analysed independently from RCTs. Secondly, the number of studies and the total sample size were low. This may have reduced the probability of finding significant results for both efficacy and safety outcomes. Also, we were not able to run separate analyses by complete or partial clinical and radiological responses. Finally, specific doses of antimicrobials and duration of treatments were heterogeneous across studies. However, the direction of effects across different treatments, designs, doses and durations of treatment were similar across studies.

Previous reviews indicated that the choice of therapy will often be directed by available therapy [6,7]. In our systematic review, the available evidence fails to identify a superior regimen in terms of relative efficacy or safety for the treatment of cerebral toxoplasmosis. Although current evidence does not allow for a definitive recommendation, use of TMP-SMX as a preferred treatment option in HIV-associated cerebral toxoplasmosis is consistent with the available data and associated practical issues. Larger comparative studies are needed, particularly in developing countries.

\section{Acknowledgements}

Conflicts of interest: None of the authors has a conflict of interest to disclose. PT is currently an employee of Avery Dennison Corporation.

Financial disclosure: No funding was obtained for this study.

\section{References}

1 Antinori A, Larussa D, Cingolani A et al. Prevalence, associated factors, and prognostic determinants of AIDSrelated toxoplasmic encephalitis in the era of advanced highly active antiretroviral therapy. Clin Infect Dis 2004; 39: 1681-1691.

2 Vidal JE, Oliveira AC. AIDS-related cerebral toxoplasmosis in Sao Paulo State, Brazil: marked improvements in the highly active antiretroviral therapy-era but the challenges continue. Braz J Infect Dis 2013; 17: 379-380.

3 Riveiro-Barciela M, Falco V, Burgos J et al. Neurological opportunistic infections and neurological immune reconstitution syndrome: impact of one decade of highly active antiretroviral treatment in a tertiary hospital. HIV Med 2013; 14: 21-30.

4 Vidal JE, Hernandez AV, de Oliveira AC, Dauar RF, Barbosa SP Jr, Focaccia R. Cerebral toxoplasmosis in HIV-positive patients in Brazil: clinical features and predictors of treatment response in the HAART era. AIDS Patient Care STDS 2005; 19: 626-634.

5 Rutsaert J, Melot C, Ectors MP, Cornil A, De Prez C, Flament Durand J. Complications infectieuses pulmonaires et neurologiques d'un sarcome de Kaposi. Corrélation anatomoclinique avec étude ultrastructurale. Ann Anat Pathol, 1980;25:125-138.

6 Dedicoat M, Livesley N. Management of toxoplasmic encephalitis in HIV-infected adults (with an emphasis on resource-poor settings). Cochrane Database Syst Rev, 2006. doi: 10.1002/14651858.CD005420.pub2

7 Yan J, Huang B, Liu G et al. Meta-analysis of prevention and treatment of toxoplasmic encephalitis in HIV-infected patients. Acta Trop 2013; 127: 236-244.

8 European AIDS Clinical Society Guidelines Clinical Management and Treatment of HIV Infected Adults in Europe. 7.1 ed. Vol 2015, 2014.

9 Panel on Antiretroviral Guidelines for Adults and Adolescents. Guidelines for the use of antiretroviral agents in 
HIV-1-infected adults and adolescents. Department of Health and Human Services 2015; 2015: 1-161.

10 Nelson M, Dockrell D, Edwards S et al. British HIV Association and British Infection Association guidelines for the treatment of opportunistic infection in HIV-seropositive individuals 2011. HIV Med 2011;12:(Suppl 2): $1-140$.

11 Gilbert DN, Chambers HF, Eliopoulos GM, Saag MS. The Sanford guide to antimicrobial therapy. 45th ed. Antimicrobial Therapy, Inc, Sperryville, VA, USA; 2015.

12 Wells GA, Shea B, O'Connell D et al. The Newcastle-Ottawa Scale (NOS) for assessing the quality of nonrandomised studies in meta-analyses. Available at: http://www.ohri.ca/ programs/clinical_epidemiology/oxford.asp. Vol 2014. (accessed 30 January 2016).

13 Higgins JP, Altman DG, Gotzsche PC et al. The Cochrane Collaboration's tool for assessing risk of bias in randomised trials. BMJ 2011; 343: d5928.

14 Moher D, Liberati A, Tetzlaff J, Altman DG, Group P. Preferred reporting items for systematic reviews and meta-analyses: the PRISMA statement. PLoS Med 2009;6:e1000097.

15 DerSimonian R, Laird N. Meta-analysis in clinical trials. Control Clin Trials 1986; 7: 177-188.

16 Egger M, Davey Smith G, Schneider M, Minder C. Bias in meta-analysis detected by a simple, graphical test. $B M J$ 1997;315:629-634.

17 Chirgwin K, Hafner R, Leport C et al. Randomized phase II trial of atovaquone with pyrimethamine or sulfadiazine for treatment of toxoplasmic encephalitis in patients with acquired immunodeficiency syndrome: ACTG 237/ANRS 039 Study. AIDS Clinical Trials Group 237/Agence Nationale de Recherche sur le SIDA, Essai 039.. Clin Infect Dis 2002; 34: 1243-1250.

18 Dannemann B, McCutchan JA, Israelski D et al. Treatment of toxoplasmic encephalitis in patients with AIDS. A randomized trial comparing pyrimethamine plus clindamycin to pyrimethamine plus sulfadiazine. The California Collaborative Treatment Group. Ann Intern Med 1992; 116: 33-43.

19 Katlama C, De Wit S, O’Doherty E, Van Glabeke M, Clumeck N. Pyrimethamine-clindamycin vs. pyrimethamine-

sulfadiazine as acute and long-term therapy for toxoplasmic encephalitis in patients with AIDS. Clin Infect Dis 1996; 22: 268-275.

20 Kongsaengdao S, Samintarapanya K, Oranratnachai K, Prapakarn W, Apichartpiyakul C. Randomized controlled trial of pyrimethamine plus sulfadiazine versus trimethoprim plus sulfamethoxazole for treatment of toxoplasmic encephalitis in AIDS patients. J Int Assoc Physicians AIDS Care 2008; 7: $11-16$.

21 Torre D, Casari S, Speranza F et al. Randomized trial of trimethoprim-sulfamethoxazole versus pyrimethaminesulfadiazine for therapy of toxoplasmic encephalitis in patients with AIDS. Italian Collaborative Study Group. Antimicrob Agents Chemother 1998; 42: 1346-1349.

22 Arens J, Barnes K, Crowley N, Maartens G. Treating AIDSassociated cerebral toxoplasmosis - pyrimethamine plus sulfadiazine compared with cotrimoxazole, and outcome with adjunctive glucocorticoids. South African medical journal $=$. Suid-Afrikaanse tydskrif vir geneeskunde 2007; 97: 956-958.

23 Caumes E, Bocquet H, Guermonprez G et al. Adverse cutaneous reactions to pyrimethamine/sulfadiazine and pyrimethamine/clindamycin in patients with AIDS and toxoplasmic encephalitis. Clin Infect Dis 1995; 21: 656658.

24 Ruf B, Pohle HD. Role of clindamycin in the treatment of acute toxoplasmosis of the central nervous system. Eur J Clin Microbiol Infect Dis 1991; 10: 183-186.

25 Navia BA, Petito CK, Gold JW, Cho ES, Jordan BD, Price RW. Cerebral toxoplasmosis complicating the acquired immune deficiency syndrome: clinical and neuropathological findings in 27 patients. Ann Neurol 1986; 19: 224-238.

26 Renold C, Sugar A, Chave JP et al. Toxoplasma encephalitis in patients with the acquired immunodeficiency syndrome. Medicine (Baltimore) 1992; 71: 224-239.

27 San-Andres FJ, Rubio R, Castilla J et al. Incidence of acquired immunodeficiency syndrome-associated opportunistic diseases and the effect of treatment on a cohort of 1115 patients infected with human immunodeficiency virus, 1989-1997. Clin Infect Dis 2003; 36: 1177-1185.

28 Manzardo C, Del Mar Ortega M, Sued O, Garcia F, Moreno A, Miro JM. Central nervous system opportunistic infections in developed countries in the highly active antiretroviral therapy era. J Neurovirol 2005;11(Suppl 3):72-82.

29 Levy RM, Bredesen DE. Central nervous system dysfunction in acquired immunodeficiency syndrome. J Acquir Immune Defic Syndr 1988; 1: 41-64.

30 Luft BJ, Hafner R, Korzun AH et al. Toxoplasmic encephalitis in patients with the acquired immunodeficiency syndrome. Members of the ACTG 077p/ANRS 009 Study Team. N Engl J Med 1993; 329: 995-1000.

31 Saadani Hassani A, Marston BJ. Impact of cotrimoxazole and insecticide-treated nets for malaria prevention on key outcomes among HIV-infected adults in low- and middleincome countries: a systematic review. J Acquir Immune Defic Syndr 2015;68(Suppl 3):S306-S317.

\section{Supporting Information}

Additional Supporting Information may be found in the online version of this article at the publisher's web-site:

Figure S1. (A) Skin rash P-C vs P-S. (B) Skin rash TMPSMX vs P-S.

Figure S2. Gastrointestinal impairment P-C vs P-S. 
Figure S3. Drug discontinuation due to adverse events P$C$ vs P-S.

Figure S4. Liver impairment P-C vs P-S.

Data S1. PubMed search strategy.
Table S1. (A) Study Quality assessment using NewcastleOttawa scale for cohort studies. (B) Study Quality assessment using Cochrane risk of bias tool for RCTs. 